\title{
NGHIÊN CỨU TİNH TRẠNG TĂNG CƯỜNG METHYL HÓA GEN CDH1 Ở BỆNH NHÂN UNG THƯ DẠ DÀY LAN TỎA
}

\author{
Ngô Diệu Hoa1, Đặng Thị Ngọc Dung ${ }^{1, \bowtie}$, Hán Minh Thủy', \\ Lê Thanh Hương ${ }^{2}$, Tạ Thành Văn ${ }^{1}$ \\ ${ }^{1}$ Trường Đại học Y Hà Nội \\ ${ }^{2}$ Bệnh viện Quốc tế Vinmec
}

Ung thư dạ dày, đặc biệt là ung thư dạ dày lan tỏa, là một bệnh lý ác tính đường tiêu hóa thường gặp có tiên lượng còn xấu, khởi phát bệnh sớm, thường phát hiện muộn khi ung thư đã di căn. Gen CDH1 mã hóa protein E-cadherin, đóng vai trò quan trọng trong sụ̣ kết dính giữa các tế bào biểu mô, mất biểu hiện protein E-cadherin dẫn đến tăng sụ tiến triển và di căn khối u. Đột biến gen CDH1 thường là đột biến điểm và dạng dị hợp tử, vì vậy, muốn biểu hiện bệnh cần có một cơ chế thứ hai, gọi là "second hit". Tăng cường methyl hóa ở vùng promoter gen $\mathrm{CDH} 1$ được coi là cơ chế "second hit" hay gặp nhất cùng với đột biến mầm gây nên ung thư dạ dày lan tỏa. Nghiên cứu xác định tình trạng tăng cường methyl hóa $A D N$ vùng promoter gen $C D H 1$ bằng sử dụng PCR đặc hiệu methyl (MSP) sau khi chuyển bisulfit trên 44 bệnh nhân được chẩn đoán UTDD lan tỏa. Tỷ lệ methyl hóa trong vùng mô ung thư $(86,4 \%)$ cao hơn so với tỷ lệ methyl hóa trong vùng mô lành $(59,1 \%)$, sự khác biệt có ý nghĩa thống kê ( $p=0,034)$. Những nghiên cứu về methyl hóa giữa vùng mô u và mô lân cận, giữa người bị bệnh ung thư và người bình thường với sự chuẩn hóa về độ nhạy và độ đặc hiệu để tạo ra một chất chỉ thị giúp sàng lọc nguy co UTDD lan tỏa, mở ra nhiều hy vọng trong điều trị đích bệnh UTDD lan tỏa.

Từ khóa: Ung thư dạ dày lan tỏa, UTDD, gen CDH1, methyl hóa.

\section{I. ĐẠT VẤN ĐỀ}

Ung thư dạ dày là loại ung thư thường gặp, là nguyên nhân gây tử vong đứng thứ ba trong các loại ung thư. Năm 2018 trên thế giới có khoảng 783.000 trường hợp tử vong do ung thư dạ dày, đặc biệt là nguyên nhân hàng đầu gây tử vong do ung thư ở các quốc gia Đông Nam Á. ${ }^{1}$ Việt Nam là một trong những nước thuộc khu vực có nguy cơ ung thư dạ dày trung bình cao, với tỷ lệ mắc chuẩn hóa theo tuổi là 21,8 ở nam và 10,0 ở nữ mỗi 100.000 dân. ${ }^{2}$ Theo phân loại của Lauren (1965) ung thư dạ dày gồm 3 thể: thể ruột, thể lan tỏa và thể hỗn hợp. Ung thư dạ dày lan tỏa đã được chứng minh có liên quan đến đột biến gen CDH1 lần đầu tiên vào năm 1998 trong 1 gia đình người New Zealand. ${ }^{3}$ Có nhiều

Tác giả liên hệ: Đặng Thị Ngọc Dung

Trường Đại học Y Hà Nội

Email: dzunghmu@gmail.com

Ngày nhận: 12/04/2021

Ngày được chấp nhận: 30/04/2021 nghiên cứu đã chứng minh rằng sự tăng cường methyl hóa ở vùng promoter của gen $\mathrm{CDH} 1$ là cơ chế phân tử thứ hai kết hợp với đột biến dòng mầm gen $\mathrm{CDH} 1$ để hình thành UTDD lan tỏa. ${ }^{4,5}$

Gene CDH1 nằm trên NST số 16q22.1, gồm 16 exon, mã hóa protein kết dính ngoại bào E-cadherin, protein xuyên màng này có chức năng như 1 chất ức chế ung thư, đóng vai trò quan trọng trong duy trì cấu trúc biểu mô. ${ }^{6}$ Tăng cường methyl hóa đảo $\mathrm{CpG}$ ở vùng promoter của gen $\mathrm{CDH} 1$ được coi là cơ chế ngoại sinh phổ biến trong UTDD lan tỏa.

Tình trạng tăng cường methyl hóa gen $\mathrm{CDH} 1$ đã được đề cập đến trong nhiều nghiên cứu trên thế giới. Tuy nhiên, tình trạng này phân bố khác nhau giữa các chủng tộc, chịu sự ảnh hưởng của yếu tố môi trường và yếu tố di truyền. Vì vậy, chúng tôi tiến hành nghiên cứu: "Nghiên cứu mức độ methyl hóa gen CDH1 ở bệnh nhân ung thư dạ dày lan tỏa ở Việt Nam". 


\section{II. ĐÓI TƯỢNG VÀ PHƯƠNG PHÁP}

\section{1. Đối tượng}

\section{Thiết kế nghiên cứu:}

Nghiên cứu mô tả cắt ngang, từ tháng 6 năm 2017 đến tháng 8 năm 2019 tại 4 bệnh viện Bệnh viện K3, Bệnh viện Đại Học Y Hà Nội, Bệnh viện 108 và Bệnh viện Việt Đức.

\section{Đối tượng nghiên cứu}

Tiêu chuẩn lựa chọn: 44 bệnh nhân được lựa chọn theo các tiêu chí:

Được chẩn đoán là ung thư dạ dày lan tỏa bằng mô bệnh học theo tiêu chuẩn phân loại của WHO (2010) bao gồm: ung thư biểu mô thể tế bào nhẫn và ung thư kém kết dính.

Được sự đồng ý tham gia nghiên cứu của bệnh nhân.

Tiêu chuẩn loại trừ

Bệnh nhân, gia đình bệnh nhân không đồng ý tham gia nghiên cứu.

Không đủ hồ sơ và thông tin bệnh nhân ở thời điểm kết thúc nghiên cứu.

\section{Phương pháp}

\section{Biến số, chỉ số nghiên cứu}

Methyl hóa (có tăng cường methyl hóa): được xác định khi có mặt 2 đoạn khuyếch đại methyl và unmethyl trên hình ảnh điện di.

Unmethyl hóa (không có sự tăng cường methyl hóa) được xác định khi chỉ có mặt đoạn khuyếch đại unmethyl trên hình ảnh điện di.

Cách loại trừ sai số: Tiến hành làm PCR 2 lần cùng 1 mẫu sau đó điện di lấy kết quả, đồng thời tiến hành giải trình tự ngẫu nhiên $10 \%$ số mẫu để xác nhận kết quả.

\section{Cách lấy mẫu bệnh phẩm}

Nghiên cứu lấy mẫu bệnh phẩm mô dạ dày gồm cả vùng mô bệnh lý và mô lành liền kề ở những bệnh nhân được chẩn đoán ung thư dạ dày lan tỏa có nội soi dạ dày hoặc phẫu thuật.
Mô lành lân cận: Các mô lành liền kề được lấy từ một khu vực cách mép khối $\mathrm{u} 1 \mathrm{~cm}$ và được bác sĩ giải phẫu bệnh xác nhận.

Mẫu bệnh phẩm được lấy từ lát cắt mô paraffin, mỗi lát cắt dày $5 \mu \mathrm{m}$, mỗi bệnh nhân ung thư dạ dày lan tỏa lấy 3-5 lát cắt.

Các lắt cắt được vận chuyển bằng khay chuyên dụng của giải phẫu bệnh, có vận chuyển cùng với đá khô bên ngoài khay, sau đó về bảo quản ở tủ âm nhiệt độ $-20^{\circ} \mathrm{C}$.

\section{Tách chiết DNA mô}

DNA mô được tách chiết theo hướng dẫn của nhà sản xuất (Exgene TM FFPE Tissue DNA, Korea). Phần mô bệnh và mô lành lân cận được xử lý bằng 1000 ul buffer DP, 180 ul buffer FPL, 20 ul Proteinase $\mathrm{K}$, ủ trong $56^{\circ} \mathrm{C}$ trong 1 giờ, sau đó ủ trong $90^{\circ} \mathrm{C}$ trong 1 giờ. Sau đó thêm 200 ul buffer FPB, bufer BW, TW, thu được DNA mô bằng cách thêm 50 ul buffer AE, ly tâm với tốc độ 12000 v/ph.

Nồng độ DNA thu được sẽ được đo bằng máy Nanodrop 1000 (ThermoFisher Scientific, Waltham, MA, US).

\section{Kỹ thuật chuyển bisufit:}

DNA mô sau khi được tách chiết sẽ được chuyển bifulfit bởi kit EpiMark® Bisulfite Conversion Kit, Anh.

PCR đặc hiệu methyl hóa (MSP).

Khuyếch đại đoạn đoạn trình tự dài 3000 nu (từ nucleotide 3001 đến 6001) vùng promoter gen CDH1 (NC_000016.10). Sử dụng phần mềm MethPrimer (Li Lab, UCSF để dự đoán các đảo $\mathrm{CpG}$ thuộc đoạn trình tự trên với các tiêu chuẩn (kích thước mỗi đảo $\geq 100$ bp, tỷ lệ $\mathrm{GC} \geq 50 \%$ và tỷ số $\mathrm{CpG}$ giữa giá trị quan sát trên giá trị mong đợi $\geq 0,6$ ).

Chuẩn hóa điều kiện $\mathrm{PCR}$ bằng nested $\mathrm{PCR}$ với 2 cặp mồi: 1 cặp mồi từ bài báo tham khảo, ${ }^{7}$ 1 cặp mồi tự thiết kế bằng phần mềm Bisulfite Primer Seeker cho methyl và unmethyl. 
Mồi methyl 5'-TTAGGTTAGAGGGTTATCGCGT-3' và 5'- CACTTACCCACCACCAATCAAC-3' Mồi unmethyl: 5'- TAATTTTAGGTTAGAGGGTTATTGT-3' và 5'- CACCACCAATGAACAACACA-3'.

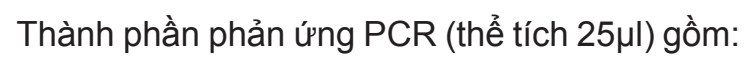

0.2 uM mỗi cặp mồi (0,5ul), 200 uM mỗi dNTP (0,5ul), 1X EpiMark Hot Start Taq Buffer (5ul), $0.625 \mathrm{U}$ của EpiMark Hot Start Taq DNA Polymerase (0,125ul), $\mathrm{H}_{2} 0: 16,375 \mathrm{ul}$, DNA (2ul).

Chu trình nhiệt: Mồi methyl: $95^{\circ} \mathrm{C} / 1$ phút, 40 chu kỳ $\left[95^{\circ} \mathrm{C} / 30\right.$ giây, $61^{\circ} \mathrm{C} / 30$ giây, $68^{\circ} \mathrm{C} / 30$ giây], $68^{\circ} \mathrm{C} / 5$ phút. Mồi unmethyl: $95^{\circ} \mathrm{C} / 1$ phút, 40 chu kỳ $\left[95^{\circ} \mathrm{C} / 30\right.$ giây, $55^{\circ} \mathrm{C} / 30$ giây, $68^{\circ} \mathrm{C}$ $/ 30$ giây], $68^{\circ} \mathrm{C} / 5$ phút.

Sản phẩm của đoạn khuếch đại mồi methyl và unmethyl tương ứng là 103 bp và 97 bp. Các sản phẩm này được điện di trên gel agarose $3 \%$. Nước không chứa enzym nuclease làm chứng âm.

\section{Xử lý số liệu}

Dữ liệu được phân tích bằng phần mềm IBM SPSS Statistic 20 (SPSS Inc, Chicago, USA). Phân tích thống kê mô tả, xác định tỷ lệ methyl và unmethyl giữa vùng mô lành, mô bệnh. Các trường hợp biểu hiện có cả methyl và unmethyl, được xác định là có tăng cường methyl hóa, các trường hợp chỉ biểu hiện là unmethyl được xác định là không có tăng cường methyl hóa. Sử dụng thống kê mô tả so sánh 2 nhóm tăng cường methyl hóa (methyl) và không tăng cường methyl hóa (unmethyl) ở mô bệnh và mô lành, đánh giá bằng Fisher's Exact Test.

\section{4. Đạo đức nghiên cứu}

Nghiên cứu tuân thủ chặt chẽ theo đạo đức nghiên cứu trong $Y$ học. Bệnh nhân và gia đình bệnh nhân hoàn toàn tự nguyện tham gia vào nghiên cứu và có quyền rút lui khỏi nghiên cứu khi không đồng ý tiếp tục tham gia. Bệnh nhân và gia đình được thông báo về kết quả xét nghiệm gen để giúp cho các bác sỹ tư vấn di truyền hoặc lựa chọn phác đồ điều trị phù hợp. Các thông tin cá nhân được đảm bảo bí mật. Nghiên cứu được tiến hành hoàn toàn vì mục đích khoa học, không vì bất kỳ mục đích nào khác.

Nghiên cứu này được tài trợ bởi Quỹ Phát triển khoa học và công nghệ Quốc gia (NAFOSTED) trong đề tài mã số 106-YS.022015.37.

\section{KẾT QUẢ}

\section{Xác định sự methyl hóa promoter CDH1 với các mẫu bệnh phẩm}

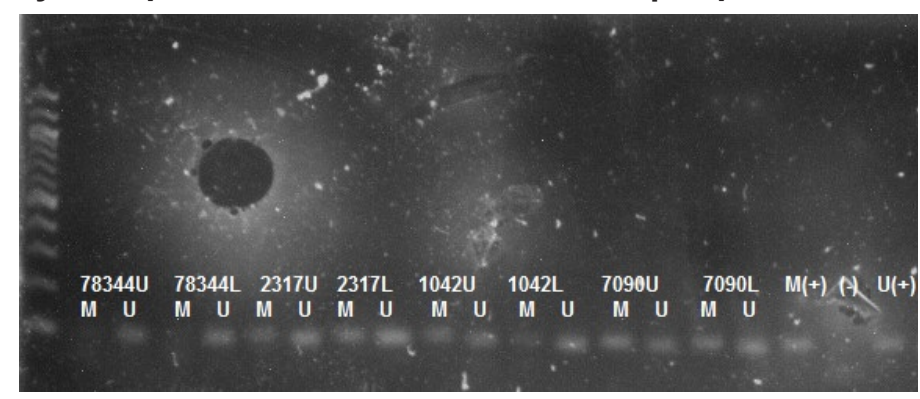

\section{Hình 1: Kết quả MSP phát hiện methyl hóa CDH1 trên bệnh nhân UTDD lan tỏa}

Giếng 1: Marker 100 bp, giếng 2-16: là mẫu của BN với mã tương ứng, giếng 17, giếng 19: chứng dương methyl và unmethyl lấy từ mẫu bệnh nhân xác nhận bằng giải trình tự, giếng 18: chứng âm là nước.

Ký hiệu: Un: unmethyl, M: methyl, L: vùng mô lành, U: là vùng mô bệnh. 
Tiến hành kiểm tra sự methyl hóa promoter CDH1 trên mẫu ung thư dạ dày lan tỏa . Kết quả trong các mẫu UTDD lan tỏa đãphát hiện có mẫu lên băng 103 bp với cặp mồi Methyl CDH1 và mẫu lên băng 97 bp với bộ mồi Unmethyl CDH1 (Hình 1).

\section{Phân tích tình trạng methyl hóa vùng promoter của gen CDH1 ở bênh nhân UTDD lan tỏa}

Bảng 1. Tỷ lệ methyl hóa và unmethyl trong mô bệnh và mô lành tương ứng

\begin{tabular}{|c|c|c|c|c|c|}
\hline & & \multicolumn{2}{|c|}{ Mô lành } & \multirow{2}{*}{ Tổng } & \multirow{2}{*}{$\mathbf{p}$} \\
\hline & & Methyl & Unmethyl & & \\
\hline \multirow{2}{*}{ Mô bệnh } & Methyl & 25 & 13 & 38 & \multirow{3}{*}{$p=0,034$} \\
\hline & Unmethyl & 1 & 5 & 6 & \\
\hline \multicolumn{2}{|c|}{ Tổng } & 26 & 18 & 44 & \\
\hline
\end{tabular}

Tỷ lệ methyl hóa của nhóm mô bệnh (38/44, 86,4\%) lớn hơn so với nhóm mô lành (26/44, 59,1\%), sự khác biệt có ý nghĩa thống kê ( $p=0,034$, Fisher test) (Bảng 1).

\section{BÀN LUÂNN}

Các phương pháp để phân tích tình trạng methyl hóa: Có rất nhiều phương pháp để phân tích tình trạng methyl hóa ở vùng promoter của 1 gen, để lựa chọn phương pháp nào phù hợp cần phải xem xét đến các yếu tố sau: mục đích của nghiên cứu (tìm những sự thay đổi về di truyền ngoại gen mới hay nghiên cứu về vị trí methyl hóa của các gen đặc hiệu đã biết), số lượng và chất lượng DNA (mô tượ hay mô paraffin), yêu cầu về độ nhạy và đặc hiệu của nghiên cứu, giá thành, hóa chất, trang thiết bị hiện có .... ${ }^{8}$ Có 3 phương pháp chính phân tích tình trạng methyl hóa ở vùng promoter của gen là PCR đặc hiệu methyl hóa (MSP), phân tích đường nóng chảy với độ phân giải cao đặc hiệu methyl (MS-HRM), PCR giải trình tự trực tiếp bisulfit (Direct bisulfite sequencing PCR) trong đó độ nhạy và độ đặc hiệu của phương pháp MSP kém hơn. ${ }^{9}$ Tuy nhiên, mục đích của nghiên cứu là xác định tình trạng methyl hóa của gen CDH1 (gen đặc hiệu đã biết trước), chỉ cần định tính sự có mặt của methyl trên vùng promoter của gen này trên mẫu bệnh nhân, cách thực hiện đơn giản, không cần các phần mềm phân tích phức tạp, giá thành hợp lý. Vì vậy, nhóm

nghiên cứu chọn phương pháp PCR đặc hiệu methyl hóa (MSP). Phương pháp MSP: dựa trên một phản ứng hóa học của sodium bisulfit với DNA, phản ứng này sẽ chuyển cytosines không bị methyl hóa trong dinucleotide CpG thành uracil hoặc UpG. Tuy nhiên, các cytosine bị methyl hóa sẽ không bị chuyển đổi trong quá trình này, và các đoạn mồi được thiết kế sẽ gối lên trình tự $\mathrm{CpG}$ quan tâm, cho phép xác định tình trạng methyl hóa của ADN như methyl hóa hay không methyl hóa.

Trong nghiên cứu của chúng tôi đã chuẩn hóa và xác định được tình trạng methyl và unmethyl trên mô của 44 bệnh nhân UTDD lan tỏa, trong đó tỷ lệ methyl hóa chiếm $86,4 \%$. Tỷ lệ này phù hợp với tác giả F. Graziano (19/24: $79,17 \%$ ) và cao hơn nghiên cứu của Haroon Rashid (52/80: 65\%).4,10 Điều này có thể do lượng mẫu của nghiên cứu của chúng tôi còn thấp, cần phải làm trên số lượng lớn hơn.Tỷ lệ methyl hóa trong vùng ung thư $(86,4 \%)$ cao hơn so với tỷ lệ methyl hóa trong vùng tế bào lành $(59,1 \%)$, sự khác biệt có ý nghĩa thống kê $(p=0.034)$. Tỷ lệ này phù hợp với nghiên cứu của Haroon Rashid, năm 2016 trên bệnh nhân 
ung thư dạ dày lan tỏa, ${ }^{4}$ tỷ lệ trên mô bệnh nhân viêm dạ dày mạn tính (41\%) của Gyeong Hoon Kang năm 2003. ${ }^{11}$

Ứng dụng trong nghiên cứu tình trạng methyl hóa ở vùng promoter của gen $\mathrm{CDH} 1$ : Methyl hóa nổi lên như một cơ chế gây im lặng các gen ức chế khối $u$, có thể sinh ung thư. Nghiên cứu về sự đảo ngược tình trạng methyl hóa trên mô hình tiền lâm sàng giúp phát triển liệu pháp điều trị đích. Liệu pháp điều trị đích sử dụng các chất có khả năng demethyl hóa như 5-aza-2-deoxycytidine (5-aza-dC) có thể áp dụng cho những bệnh nhân bị methyl hóa nhiều gen ức chế khối u trong đó có gen CDH1.12,13

Như vậy, nghiên cứu đã bước đầu đánh giá được tình trạng tăng cường methyl hóa ở vùng mô bệnh và mô lành tương ứng của bệnh nhân ung thư dạ dày lan tỏa ở Việt Nam. Nghiên cứu sẽ là bước đệm để tiến hành những nghiên cứu sâu hơn liên quan đến việc đáp ứng thuốc demethyl hóa trong ung thư dạ dày lan tỏa, đưa ra một hướng đi mới trong điều trị ung thư dạ dày lan tỏa.

\section{KÉT LUẬN}

Nghiên cứu đã phát hiện tỷ lệ methyl hóa trong vùng ung thư $(86,4 \%)$ cao hơn so với tỷ lệ methyl hóa trong vùng tế bào lành $(59,1 \%)$ ở các bệnh nhân ung thư dạ dày lan tỏa, sự khác biệt có ý nghĩa thống kê ( $p=0,034)$.

\section{Lò̀i cảm ơn}

Nghiên cứu được hỗ trợ với kinh phí của quỹ Nafosted với đề tài khoa học cấp Bộ Y tế "Nghiên cứu tính đa hình và nhạy cảm của một số gen liên quan đến nguy cơ ung thư dạ dày trên người Việt Nam" và sự giúp đỡ của Trung tâm Kiểm chuẩn chất lượng xét nghiệm y học, Trường Đại Học Y Hà Nội.

\section{TÀI LIẸU THAM KHẢO}

1. Bray F, Ferlay J, Soerjomataram I, Siegel RL, Torre LA, Jemal A. Global cancer statistics 2018: GLOBOCAN estimates of incidence and mortality worldwide for 36 cancers in 185 countries. CA: a Cancer Journal for clinicians. 2018;68(6):394-424.

2. Fock KM, Ang TL. Epidemiology of Helicobacter pylori infection and gastric cancer in Asia. Journal of gastroenterology and hepatology. 2010;25(3):479-486.

3. Guilford P, Hopkins J, Harraway J, et al. $\mathrm{E}$-cadherin germline mutations in familial gastric cancer. Nature. 1998;392(6674):402-405.

4. Rashid H, Alam K, Afroze D, Yousuf A, Banday M, Kawoosa F. Hypermethylation Status of E-Cadherin Gene in Gastric Cancer Patients in a High Incidence Area. Asian Pacific journal of cancer prevention: APJCP. 2016;17(6):27572760.

5. Grady WM, Willis J, Guilford PJ, et al. Methylation of the CDH1 promoter as the second genetic hit in hereditary diffuse gastric cancer. Nature genetics. 2000;26(1):16-17.

6. Black MD, Kaneshiro R, Lai JI, Shimizu DM. Hereditary diffuse gastric cancer associated with E-cadherin germline mutation: a case report. Hawai'i journal of medicine \& public health: a journal of Asia Pacific Medicine \& Public Health. 2014;73(7):204-207.

7. Kague E, Thomazini CM, Pardini MI, Carvalho F, Leite CV, Pinheiro NA. Methylation status of $\mathrm{CDH} 1$ gene in samples of gastric mucous from Brazilian patients with chronic gastritis infected by Helicobacter pylori. Arq Gastroenterol. 2010;47(1):7-12.

8. Corso G, Roviello F, Paredes J, et al. Characterization of the P373L E-cadherin germline missense mutation and implication for clinical management. European journal 
of surgical oncology: the journal of the European Society of Surgical Oncology and the British Association of Surgical Oncology. 2007;33(9):1061-1067.

9. Barber $\mathrm{M}$, Murrell $\mathrm{A}$, Ito $\mathrm{Y}$, et al. Mechanisms and sequelae of $E$-cadherin silencing in hereditary diffuse gastric cancer. $J$ Pathol. 2008;216(3):295-306.

10. Graziano F, Arduini F, Ruzzo A, et al. Combined analysis of E-cadherin gene $(\mathrm{CDH} 1)$ promoter hypermethylation and E-cadherin protein expression in patients with gastric cancer: implications for treatment with demethylating drugs. Annals of oncology : official journal of the European Society for Medical Oncology. 2004;15(3):489-492.
11. Kang $\mathrm{GH}$, Lee $\mathrm{HJ}$, Hwang $\mathrm{KS}$, Lee $\mathrm{S}$, Kim JH, Kim JS. Aberrant CpG island hypermethylation of chronic gastritis, in relation to aging, gender, intestinal metaplasia, and chronic inflammation. The American journal of pathology. 2003;163(4):1551-1556.

12. Galmiche A, Rassow J, Doye A, et al. The N-terminal $34 \mathrm{kDa}$ fragment of Helicobacter pylori vacuolating cytotoxin targets mitochondria and induces cytochrome c release. Embo $j$. 2000;19(23):6361-6370.

13. Keates S, Keates AC, Warny M, Peek RM, Jr., Murray PG, Kelly CP. Differential activation of mitogen-activated protein kinases in AGS gastric epithelial cells by cag+ and cag- Helicobacter pylori. J Immunol. 1999;163(10):5552-5559.

\section{Summary}

\section{HYPERMETHYLATION STATUS OF CDH1 GENE IN PATIENTS WITH DIFFUSE GASTRIC CANCER}

Gastric cancer (GC), especially diffuse gastric cancer, is a common malignancy in the gastrointestinal tract with a poor prognosis, early-onset, often found late when cancer has metastasized. The $\mathrm{CDH} 1$ gene encodes the E-cadherin protein, which plays an important role in the adhesion between epithelial cells, and loses expression of the E-cadherin protein, leading to increased tumor progression and metastasis. CDH1 gene mutations are usually a point mutation and a heterozygous pattern, so a second hit mechanism is needed to manifest the disease. Hypermethylation in the CDH1 gene promoter region is considered the 'second hit' mechanism most commonly encountered with germline mutation causing diffuse gastric cancer. This study is to determined the hypermethylation of the CDH1 gene promoter region using methyl-specific PCR (MSP) after bisulfite transfer in 44 patients diagnosed with diffuse gastric cancer. The hypermethylation in the tumour region $(86.4 \%)$ was higher than the hypermethylation in the normal region (59.1\%); the difference was statistically significant $(p=0.034)$. The studies of hypermethylation between tumor regions and normal adjacent tissue, between patients with cancer and normal people with standardization of sensitivity and specificity will create an indicator to assist in screenning the risk of spreading gastric cancer and open up a hopeful new direction in the target treatment of diffuse gastric cancer.

Keywords: Diffuse gastric cancer, gastric cancer, CDH1 gene, methylation. 